\title{
Heterogeneous Photocatalysis Applied to Concrete Pavement for Air Remediation
}

\author{
M.M. Ballari, M. Hunger, G. Hüsken, and H.J.H. Brouwers
}

\begin{abstract}
In the present work the degradation of nitrogen oxides $\left(\mathrm{NO}_{\mathrm{x}}\right)$ by concrete paving stones containing $\mathrm{TiO}_{2}$ to be applied in road construction is studied. A kinetic model is proposed to describe the photocatalytic reaction of nitric oxide (NO) in a standard flow laminar photoreactor irradiated with UV lamps. In addition the influence of several parameters that can affect the performance of these stones under outdoor conditions are investigated, such as irradiance, relative humidity and wind speed. The kinetic parameters present in the NO reaction rate are estimated employing experimental data obtained in the photoreactor. The obtained model predictions employing the determined kinetic constants are in good agreement with the experimental results of NO concentration at the reactor outlet.
\end{abstract}

\section{Introduction}

Heterogeneous photocatalysis represents an emerging environmental control option for the efficient removal of chemical pollutants and it can be applied to water and air purification. This process involves a nano-solid semiconductor catalyst, regularly titanium dioxide $\left(\mathrm{TiO}_{2}\right)$, which is activated with ultraviolet light of the appropriate wavelength.

Nitrogen oxides $\left(\mathrm{NO}_{\mathrm{x}}\right)$ is the generic term for a group of highly reactive gases, most of them emitted in air in the form of nitric oxide (NO) and nitrogen dioxide $\left(\mathrm{NO}_{2}\right)$. Nitrogen oxides form when fuel is burned at high temperatures, as is the case in combustion processes in automobiles. $\mathrm{NO}_{\mathrm{x}}$ causes a wide variety of health and environmental impacts, like the formation of tropospheric ozone and urban smog through photochemical reactions with hydrocarbons. Furthermore, $\mathrm{NO}_{\mathrm{x}}$ together with $\mathrm{SO}_{\mathrm{x}}$ (sulfur dioxide and sulfur trioxide) is the major contributor to the "acid rain", one of the most serious environmental problems across the world.

The European Union (EU) has taken important steps over the past decade leading to a decrease in the emissions to air and water of a number of pollutants. One of its directives (1999/30/EC) establishes limit values for concentrations of

M.M. Ballari, M. Hunger, G. Hüsken, and H.J.H. Brouwers

Department of Construction Management \& Engineering, Faculty of Engineering

Technology, University of Twente, Enschede, The Netherlands

e-mail: M.Ballari@ctw.utwente.nl

www. utwente.nl 
sulphur dioxide, nitrogen dioxide and oxides of nitrogen, particulate matter and lead in ambient air. Some of the pollutant emissions have since become more or less manageable; however particulates, $\mathrm{NO}_{\mathrm{x}}$ and smog are still problematic.

The development of innovative materials that can be easily applied on structures, with both de-soiling and de-polluting properties, is a significant step towards improvements of air quality. The use of $\mathrm{TiO}_{2}$ photocatalyst in combination with cementitius and other construction materials has shown a favorable effect in the removal of nitrogen oxides.

In the present work the degradation of $\mathrm{NO}_{x}$ compounds employing concrete paving stones with $\mathrm{TiO}_{2}$ to be applied in road construction is studied. The experiments were carried out in a photoreactor designed according to the standard ISO 22197-1 (2007) to assess these kind of photocatalytic materials employing NO as the pollutant source. A kinetic model is proposed to describe the photocatalytic oxidation of $\mathrm{NO}_{\mathrm{x}}$ and the influence of several parameters that can affect the performance of these stones under outdoor conditions, such as irradiance, relative humidity and wind speed. A reaction rate expression for the NO oxidation is postulated and the kinetic parameters are determined employing the experimental data. Finally the model predictions with the estimated kinetic constants are compared with the experimental results obtaining a good agreement between them.

\section{Experimental Setup}

The standard ISO 22197-1 (2007) serves as a sound basis for measurements, its recommendations were largely followed for the practical conduction of the present study. The applied apparatus is composed of a planar reactor cell housing the concrete stone sample, a suitable UV-A light source, a chemiluminescent $\mathrm{NO}_{\mathrm{x}}$ analyzer, and an appropriate gas supply (Figure 1).

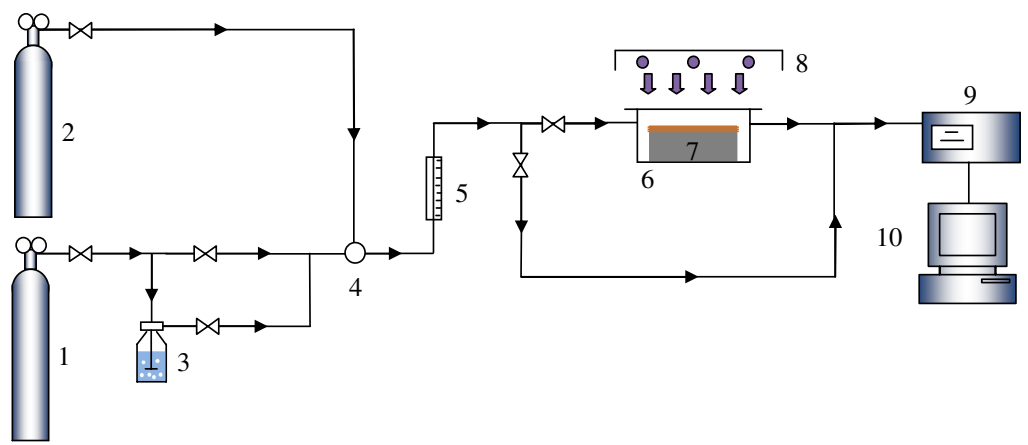

Fig. 1 Schematic representation of the experimental setup. 1. Synthetic air. 2. NO source. 3. Gas washing bottle. 4. Temperature and relative humidity sensor. 5. Flow controller. 6. Gas photoreactor. 7. Paving stone sample. 8 Light source. 9. $\mathrm{NO}_{x}$ analyzer. 10. Computer

Table 1 shows the main characteristics, dimensions and operating conditions of the experimental setup that were employed to carry out the photocatalytic NO degradation experiments. 
Table 1 Experimental setup main characteristics and operating conditions

\begin{tabular}{lll}
\hline Description & & Value \\
\hline Reactor & Length (L) & $2 \mathrm{dm}$ \\
& Width (B) & $1 \mathrm{dm}$ \\
& Height (H) & $0.02-0.04 \mathrm{dm}$ \\
& Volume ( $\left.\mathrm{V}_{\text {reactor }}\right)$ & $0.04-0.08 \mathrm{dm}^{3}$ \\
Photocatalytic stone & Length (L) & $2 \mathrm{dm}$ \\
& Width (B) & $1 \mathrm{dm}$ \\
Lamps: Philips Compact S $\times 3$ & Input power & $25 \mathrm{~W}$ \\
Flow rate (Q) & Emission wavelength & $300-400 \mathrm{~nm}^{-1}$ \\
Relative Humidity $(\mathrm{RH})$ & & $3-5 \mathrm{dm}^{3} \mathrm{~min}^{-1}$ \\
Inlet NO concentration $\left(\mathrm{C}_{\mathrm{NO}, \text { in }}\right)$ & & $10-80 \%$ \\
Irradiance flux (E) & & $0.1-1 \mathrm{ppm}^{-2}$ \\
\hline
\end{tabular}

\section{Theoretical Model}

The kinetic expression proposed for the NO degradation reaction rate is the corresponding to the Langmuir-Hinshelwood model [1,7], which is widely employed for the photocatalytic degradation of other contaminants $[2,6,8]$. However the reaction rate should be expressed as a superficial rate for a gas-solid heterogeneous system $[3,4]$. In addition, water competes with NO for free active sites at the catalyst surface and therefore it can be considered as an additional reactant [8]. Following this model applied to a heterogeneous reaction, the Langmuir-Hinshelwood kinetic model for NO disappearance rate per unit area of active surface reads:

$$
\mathrm{r}_{\mathrm{NO}}=-\frac{\mathrm{kK}_{\mathrm{NO}} \mathrm{C}_{\mathrm{NO}}}{1+\mathrm{K}_{\mathrm{NO}} \mathrm{C}_{\mathrm{NO}}+\mathrm{K}_{\mathrm{w}} \mathrm{C}_{\mathrm{w}}}
$$

where $r_{N O}$ is the superficial reaction rate $\left(\right.$ mole $\mathrm{dm}^{-2} \min ^{-1}$ ) of NO. $\mathrm{C}_{\mathrm{NO}}$ and $\mathrm{C}_{\mathrm{w}}$ are the corresponding molar concentration $\left(\right.$ mole $\mathrm{dm}^{-3}$ ) of $\mathrm{NO}$ and water. $\mathrm{k}$ is the reaction rate constant $\left(\right.$ mole $\left.\mathrm{dm}^{-2} \min ^{-1}\right) . \mathrm{K}_{\mathrm{NO}}$ and $\mathrm{K}_{\mathrm{w}}$ are the adsorption equilibrium constant $\left(\mathrm{dm}^{3} \mathrm{~mole}^{-1}\right)$ for $\mathrm{NO}$ and for water respectively.

Regarding the UV light effect, it is supposed that the irradiance only has an influence on the reaction rate constant $(\mathrm{k})$. Therefore a mathematical expression of the reaction constant $\mathrm{k}$ in function of the radiative flux $\mathrm{E}$ is proposed:

$$
\mathrm{k}=\mathrm{k}^{\prime}(-1+\sqrt{1+\alpha \mathrm{E}})
$$

with $\mathrm{k}^{\prime}$ (mole $\left.\mathrm{dm}^{-2} \mathrm{~min}^{-1}\right)$ and $\alpha\left(\mathrm{dm}^{2} \mathrm{~W}^{-1}\right)$ being factors to be fitted from the experiments. This expression takes account of the linear and the square root dependency of the reaction rate with the light intensity, that have announced in several publications [3] for high and low irradiance respectively. When UV-radiation is absent, i.e. $\mathrm{E}=0$, the reaction rate becomes zero. For small E, Eq. (2) tends $\mathrm{k}^{\prime} \alpha \mathrm{E} / 2$, and for large $\mathrm{E}$ it tends to $\mathrm{k}^{\prime} \sqrt{\alpha \mathrm{E}}$. 
The NO balance equations for a plug flow reactor reads:

$$
\mathrm{v}_{\text {air }} \frac{\mathrm{dC}_{\mathrm{NO}}}{\mathrm{dx}}=\mathrm{a}_{\mathrm{v}} \mathrm{r}_{\mathrm{NO}}
$$

where $v_{\text {air }}$ is the air velocity $\left(\mathrm{dm} \min ^{-1}\right)$ in the reactor and $a_{v}$ is the active surface area per unit reactor volume $\left(\mathrm{dm}^{-1}\right)$. The reactor inlet condition is:

$$
\mathrm{C}_{\mathrm{NO}}(\mathrm{x}=0)=\mathrm{C}_{\mathrm{NO}, \text { in }}
$$

\section{Kinetic Parameters Estimation}

To solve the NO mass balance with the complete kinetic expression, a discretization of the differential equation (Eq. (3)) can be applied (Euler method). Then the optimization of all kinetic parameters present in the reaction rate can be achieved employing the "solver" tool of Excel. The result of this estimation is shown in Table 2.

\section{Experimental Results Versus Model Prediction}

It is possible to analyze the effect of different operating variables on the system by resorting the estimated kinetic parameters from the complete model. This analysis can include a comparison between simulated values obtained with the model and experimental measurements.

Table 2 Non linear parameters optimization (based on 36 experimental results) employing the Excel Solver tool and the numerical solution of the NO differential mass balance performing a forward discretization

\begin{tabular}{ll}
\hline Parameter & Value \\
\hline $\mathrm{k}^{\prime}\left(\right.$ mole dm$\left.^{-2} \min ^{-1}\right)$ & $7.24 \times 10^{-10}$ \\
$\alpha\left(\mathrm{dm}^{2} \mathrm{~W}^{-1}\right)$ & $1.40 \times 10^{6}$ \\
$\mathrm{~K}_{\mathrm{NO}}\left(\mathrm{dm}^{3} \mathrm{~mole}^{-1}\right)$ & $2.50 \times 10^{10}$ \\
$\mathrm{~K}_{\mathrm{w}}\left(\mathrm{dm}^{3} \mathrm{~mole}^{-1}\right)$ & $7.67 \times 10^{5}$ \\
\hline
\end{tabular}

Figure 2 shows the model predictions and the experimental data corresponding to the NO outlet concentration in function of the NO inlet concentration to the reactor for two different flow rates. When the inlet concentration of NO increases, NO outlet concentration rise as well. However, as expected, decreasing the initial concentration of the pollutant the final conversion of the reacting system increases.

The effect of the flow rate is possible to analyze comparing Figures. 2(a) and (b). When the flow rate is increased the resident time in the reactor decreases. Therefore, for low flow rates a larger conversion of the pollutant is observed. 

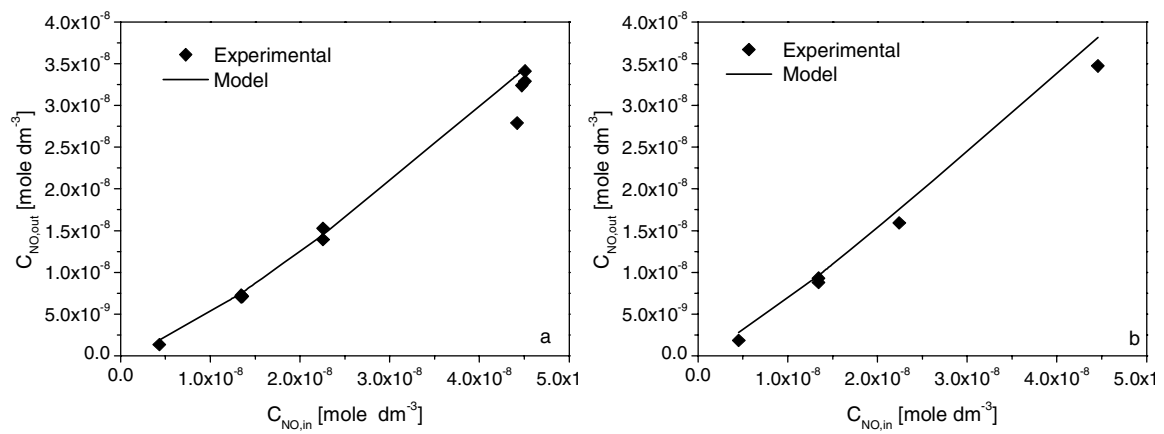

Fig. 2 Model prediction vs. experimental data. NO outlet concentration in function of the NO inlet concentration. $\mathrm{RH}=50 \%$. $E=10 \mathrm{~W} \mathrm{~m}^{-2}$. a) $\mathrm{Q}=3 \mathrm{dm}^{3} \mathrm{~min}^{-1}$. b) $\mathrm{Q}=5 \mathrm{dm}^{3} \mathrm{~min}^{-1}$

Regarding the irradiance and relative humidity effect, Figures 3(a) and (b) show the obtained results varying these two parameters, respectively. When the irradiance is increased a higher conversion of the systems is achieved. However when the relative humidity is enlarged water competes with NO for the same active site and the NO consumption declines.
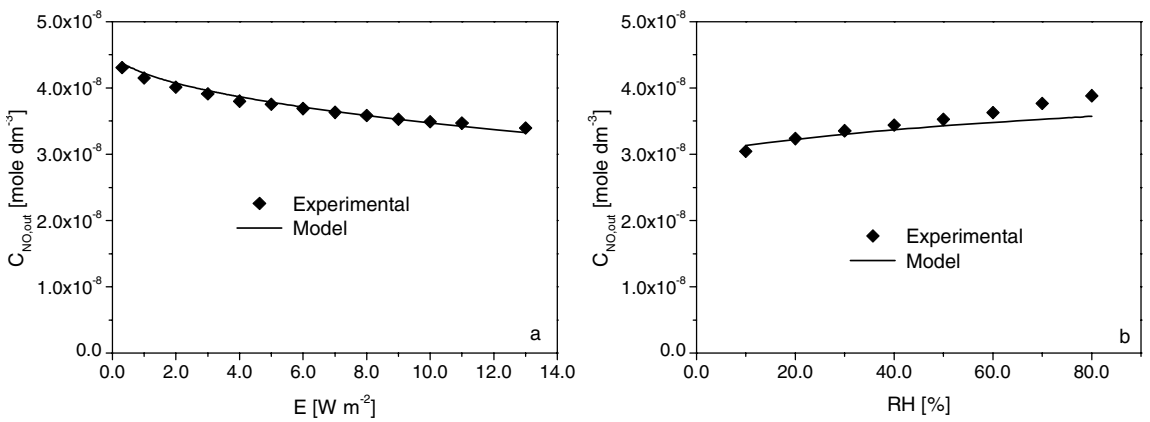

Fig. 3 Model prediction vs. experimental data. a) NO outlet concentration in function of the radiative flux. b) $\mathrm{NO}$ outlet concentration in function of the relative humidity. $\mathrm{C}_{\mathrm{No} \text {.in }}=1$ ppm. $\mathrm{Q}=3 \mathrm{dm}^{3} \min ^{-1} . \mathrm{H}=3 \mathrm{~mm}$

\section{Conclusions}

In the present work, a kinetic study of the photocatalytic degradation of nitrogen oxides was conducted. A heterogeneous kinetic expression for the NO degradation was proposed. Several experiments were carried out according to a suitable ISO standard for photocatalytic materials assessment employing only $\mathrm{NO}$ as a contaminat. Different operating conditions were selected to perform the experiments (NO inlet concentration, reactor height, flow rate, irradiance flux and relative humidity). Employing these experimental data and the reaction rate expression, the kinetic parameters were estimated for a numerical solution of the governing 
equations in the reactor, based on Langmuir-Hinshelwood kinetics. In all cases, a very good correlation between the experimental data and the computer simulation with the estimated kinetic parameters was obtained.

Acknowledgments. The authors wish to express their thanks to the following sponsors of the research group: Bouwdienst Rijkswaterstaat, Rokramix, Betoncentrale Twenthe, Graniet-Import Benelux, Kijlstra Beton, Struyk Verwo Groep, Hülskens, Insulinde, Dusseldorp Groep, Eerland Recycling, ENCI, Provincie Overijssel, Rijkswaterstaat Directie Zeeland, A\&G maasvlakte, BTE, Alvon Bouwsystemen, and V. d. Bosch Beton (chronological order of joining).

\section{References}

1. Devahasdin, S., Fan, C., Li, J.K., Chen, D.H.: $\mathrm{TiO}_{2}$ Photocatalytic Oxidation of Nitric Oxide: Transient Behavior and Reaction Kinetics. J. Photochem. and Photobiol. A Chem. 156, 161-170 (2003)

2. Dong, Y., Bai, Z., Liu, R., Zhu, T.: Decomposition of Indoor Ammonia with $\mathrm{TiO}_{2}$ Loaded Cotton Woven Fabrics Prepared by Different Textile Finishing Methods. Atm. Env. 41, 3182-3192 (2007)

3. Imoberdorf, G.E., Irazoqui, H.A., Cassano, A.E., Alfano, O.M.: Photocatalytic Degradation of Tetrachloroethylene in Gas Phase on $\mathrm{TiO}_{2}$ Films: A Kinetic Study. Ind. Eng. Chem. Res. 44, 6075-6085 (2005)

4. Levenspiel, O.: Chemical Reaction Engineering. Willey, New York (1999)

5. Lin, Y.M., Tseng, Y.H., Huang, J.H., Chao, C.C., Chen, C.C., Wang, I.: Photocatalytic Activity for Degradation of Nitrogen Oxides over Visible Light Responsive TitaniaBased Photocatalysts. Environ. Sci. Technol. 40, 1616-1621 (2006)

6. Ollis, D.F.: Photoreactors for Purification and Decontamination of Air. In: Ollis, D.F., Al-Ekabi, H. (eds.) Photocatalytic Purification and Treatment of Water and Air, pp. 481-494. Elsevier, Amsterdam (1993)

7. Wang, H., Wu, Z., Zhao, W., Guan, B.: Photocatalytic Oxidation of Nitrogen Oxides Using $\mathrm{TiO}_{2}$ Loading on Woven Glass Fabric. Chemosphere 66, 185-190 (2007)

8. Zhang, J., Hu, Y., Matsuoka, M., Yamashita, H., Minagawa, M., Hidaka, H., Anpo, M.: Relationship between the Local Structures of Titanium Oxide Photocatalysts and their Reactivities in the Decomposition of NO. J. Phys. Chem. B 105, 8395-8398 (2001) 